\title{
Proteínas estructurales y mediadores de la inflamación: marcadores para el diagnóstico postmortem de la isquemia miocárdica (estudio inmunohistoquímico).
} Structural proteins and mediators of inflammation: markers for the diagnostic postmortem of myocardial ischemia (inmunohistochemical study).

\section{J. Blanco Pampín¹, S.A. García Rivero² y R. Hinojal Fonseca ${ }^{3}$}

\section{RESUMEN}

El diagnóstico histopatológico post-mortem del infarto de miocardio presenta múltiples problemas en material humano procedente de autopsias. Hasta el presente momento, el problema no ha podido ser resuelto con el uso de las técnicas histológicas convencionales (hematoxilina-eosina, tricrómico de Masson y técnicas histoquímicas). Otra desventaja de este último método es que solo son aplicables sobre tejido fresco.

En este estudio, se han recopilado muestras pertenecientes a $\mathbf{5 0}$ corazones, procedentes de autopsias de individuos fallecidos por muerte súbita de origen cardíaco. Además, se incluyeron seis casos de infarto de miocardio macroscópico (controles positivos) y ocho casos de muertes rápidas de origen no cardíaco (controles negativos). Se ha investigado la expresión de actina, desmina, mioglobina y factores de Complemento (C5b-9) mediante el método del Complejo avidita-biotina-peroxidasa y su posible utilidad en el diagnóstico postmorten de las muertes cardíacas.

Los resultados del estudio, muestran que el método inmunohistoquímico sobre tejido fijado en formol e incluido en parafina es útil para el diagnóstico postmortem de la isquemia miocárdica.

Palabras clave: Autopsia médicolegal, diagnóstico postmortem, Inmunohistoquímica, isquemia miocárdica, muerte súbita de origen cardíaco.

\section{ABSTRACT}

Postmortem histopathological diagnosis of myocardial infarction has many problems in human material coming from autopsy. Until the present moment, this matter hasn't been resolved by conventional histological procedures (hematoxilineosin, Masson's trichrome and histochemical techniques). Another disadvantage of the enzymehistohemical technique is that it is only applicable to unfixed specimens.

In this study, 50 myocardial tissue specimens were taken at autopsy from victims who died of sudden cardiac death. In addition, six cases of macroscopic myocardial infarction (positive controls) and 8 cases of rapid and non-cardiac causes of death (negative controls) were included in the study. The expression of actin, desmin, myoglobin and Complement factor (C5b-9) by avidin-biotin-peroxidase complex method, and its possible utility in post-mortem diagnosis of human heart failure, were studied.

Results of our study, show that the inmunohistochemical method using formalin-fixed, paraffin-embebed tissue is valuable for post-mortem detection of myocardial ischemia.

Key words: Sudden cardiac death, post-mortem diagnosis, inmunohistochemistry, myocardial ischemia, medicolegal autopsy.

Correspondencia: Dr. José Blanco Pampín. Clínica Médico-Forense. Palacio de Justicia. c/ Viena s/n. 15701 SANTIAGO DE COMPOSTELA. e-mail: cmpampin@usc.es.

\footnotetext{
1 Doctor en Medicina. Especialista en Medicina Legal. Médico forense (Santiago de Compostela).

2 Especialista en Biología molecular.

3 Catedrático de Medicina Legal. Universidad de Oviedo.
} 


\section{INTRODUCCIÓN:}

Las limitaciones para el diagnóstico postmortem del infarto de miocardio mediante las técnicas histológicas convencionales han estimulado la búsqueda de nuevos métodos diagnósticos. Hasta el momento actual, tanto el diagnóstico macroscópico como microscópico no son posibles hasta que han transcurrido 6-12 horas de isquemia.

Los recientes avances en el campo de la tecnología inmunohistoquímica, su implantación prácticamente universal en los laboratorios de Patología, así como la posibilidad de obtener anticuerpos frente a una amplia variedad de antígenos nos han permitido evaluar el potencial de estas técnicas en la detección de la isquemia miocárdica en fases precoces. Por ese motivo, los métodos inmunohistoquímicos en el diagnóstico de isquemia y del infarto de miocardio han adquirido una especial relevancia dentro del campo de la Patología forense [I].

En la actualidad, los marcadores más utilizados están orientados hacia los siguientes elementos:

A) Proteínas estructurales: Diferentes estudios relativos a los cambios del citoesqueleto cardíaco y proteínas contráctiles, efectuados tanto en el modelo animal como humano, han sugerido la posibilidad de utilizar las alteraciones de ciertas proteínas como marcadores precoces para el diagnóstico postmortem de la isquemia miocárdica en casos de muerte súbita de origen cardíaco; entre estas proteínas cabe mencionar la actina [2-4], miosina [5-8], mioglobina [6,9-I I], desmina [ $10-15]$, vinculina [4], laminina [I6], troponina I [ I 7] o troponinas C y $T$ entre otras [ I I].

B) Mediadores de la inflamación: También denominados "reactantes de fase aguda" [ 8 8]; su papel en la inflamación y en la patogénesis y evolución del infarto de miocardio ha suscitado en los últimos años un creciente interés terapéutico, al haberse comprobado que la inhibición de la respuesta inflamatoria comporta una reducción del tamaño del infarto.

Su interés ha quedado patente al demostrarse alteraciones de ciertos componentes en casos de infarto de miocardio reciente, destacando la ceruloplasmina y la proteína C-reactiva [5, 6], el fibrinógeno [10, I I, 19, 20], la alfa- I-antitripsina [5], factores del complemento [5, 10, I I, 14, 21 -30], la albúmina [5, 3 I], la creatín-kinasa [I4, 32] o proteína fijadora de ácidos grasos cardíaca [33].

El presente estudio ha sido dirigido hacia aquel grupo de muertes en las cuales se sospechaba una patología de tipo isquémico, evidenciándola mediante diferentes técnicas postmortem. En este trabajo se ha intentado además, exponer una metodología de trabajo sencilla y útil para la recogida y procesado de muestras en la práctica médico forense de rutina, evaluar el papel de la isquemia miocárdida en la muerte súbita del adulto y valorar la eficacia, sensibilidad y especificidad de las técnicas inmunohistoquímicas como marcadores precoces de la isquemia miocárdica.

\section{MATERIAL Y MÉTODOS:}

El material utilizado en este estudio incluyó 64 corazones humanos, procedentes de autopsias judiciales. El grupo fue dividido básicamente, en tres categorías:

- Casos problema: constituido por un total de 50 casos pertenecientes a cadáveres de individuos que fallecieron de forma súbita. En los referidos casos, se practicó una autopsia médicolegal completa lo más precozmente posible, excluyendo convenientemente la existencia de cualquier patología (cardíaca o no) que pudiera constituir por sí misma una causa de muerte. Además de un minucioso estudio macroscópico, se llevó a cabo una completa investigación toxicológica y el correspondiente estudio histopatológico de todos los órganos. 
Controles positivos: formado por 6 casos con evidencia macroscópica de infarto de miocardio reciente, algunos de ellos documentados clínicamente que consideramos controles positivos.

Controles negativos: incluyendo otros 8 corazones procedentes de sujetos que fallecieron de forma muy rápida o instantánea (TCE abiertos o armas de fuego).

Previamente fueron excluidos 14 casos por distintos motivos: por no disponer del número de muestras suficientes para realizar el estudio inmunohistoquímico, por no estar adecuadamente fijadas, porque no eran representativas de la lesión, por encontrarse afectadas por la putrefacción o porque los resultados de la inmunohistoquímica no eran completamente satisfactorios.

Con el objeto de poner a punto la técnica inmunohistoquímica en el material recogido, se examinó la influencia del tiempo de fijación, de la digestión enzimática (tripsinización) y de la incubación en microondas en una corta serie de 15 muestras, especialmente procedentes de los controles positivos. Los tiempos de fijación incluyeron 12, 24 y 36 horas.

\section{A) Selección de casos:}

Todos los casos incluidos en el estudio (casos problema y controles positivos) fueron previamente seleccionados entre aquellos individuos que presentaban perfil de muerte súbita. La información relativa a la sintomatología se obtuvo, en la mayoría de los casos, a través de diferentes personas (familiares, testigos, médico de cabecera, policía...). Como síntomas previos a la muerte, fueron considerados aquellos que aparecieron como expresión de la descompensación aguda del paciente y que estuvieron estrechamente relacionados con su muerte. Si bien en algunos no existieron testimonios al respecto, sin embargo se consideró que el fallecimiento había sucedido de forma mas o menos brusca, dado que el individuo había sido visto vivo pocas horas antes.

De la selección de casos se decidió excluir aquellos casos en los cuales se habían practicado maniobras de reanimación cardiopulmonar, en especial ante la eventual existencia de un masaje cardíaco o la inyección intracardíaca de catecolaminas u otros fármacos, en tanto que tales maniobras pueden inducir lesiones similares a la isquemia. Teniendo en cuenta que tales maniobras, pueden dar lugar además a una deplección de ciertas proteínas estructurales como la mioglobina, consideramos que la alteración puede afectar también a la integridad de la permeabilidad del sarcolema y falsear los resultados con los anticuerpos que ensayamos. Pero no solo las lesiones traumáticas como el masaje cardíaco enérgico pueden ocasionar deplección de antígenos, sino también el efecto de la corriente eléctrica que se utiliza en las maniobras de cardioversión, o la reperfusión tisular [I l]. Por consiguiente fueron excluidos también del estudio aquellos casos de pacientes ingresados en la Unidad de Cuidados Intensivos y sometidos a medidas de soporte antes del fallecimiento.

Asimismo, algunas piezas anatómicas (corazones) disponibles en los archivos en el momento de iniciar el trabajo, fueron rechazadas por el excesivo período de fijación que sufrieron. Se consideró que tal circunstancia podía implicar disminuciones cuantitativas en muchos marcadores, dado que cuando el tiempo de fijación es prolongado, ocasiona una disminución de la eficacia del anticuerpo, alterando de forma significativa los resultados de la inmunohistoquímica.

Para evitar posibles artefactos de la técnica, decidimos no realizar inmunohistoquímica en aquellos casos que ofrecían datos de putrefacción más o menos avanzada. Si bien determinados autores han llevado a cabo este tipo de estudios [10,27], no obstante consideramos que cuando existe abundante necrosis los resultados de la inmunohistoquímica deben ser manejados e interpretados con suma precaución, ya que puede ser el origen de falsos positivos.

Se decidió no partir de la base de utilizar la clásica técnica histoquímica del TTC para identificar macroscópicamente el infarto [25, 3 I] y se realizó el estudio seleccionando siempre topográfica- 
mente las mismas 9 secciones. El TTC además, es incapaz de reconocer infartos recientes. Otras técnicas como el Van Gieson presentan claras dificultades para descubrir pequeños grupos de células dañadas. De esta manera se simplificó la técnica de estudio, despreciando el laborioso y complicado método de estas técnicas, que por otra parte poseen una sensibilidad relativamente escasa.

\section{B) Autopsia del Corazón y procedimiento de ObTención de SECCIONES de tejido Cardíaco:}

El tiempo transcurrido entre el fallecimiento y la extracción de las muestras, fue conocido con bastante exactitud en la mayor parte de los casos, no excediendo de 16 horas. Durante este tiempo el cadáver se mantuvo refrigerado a $4^{\circ} \mathrm{C}$ en el depósito.

Cada corazón objeto de estudio fue pesado, y a continuación disecado según la siguiente técnica:

a) Se obtuvieron cinco secciones transversales de ambos ventrículos, efectuando al primer corte inmediatamente por debajo del anillo fibroso de implantación. Se seleccionaron la $1^{\circ}, 3^{\circ}$ y $5^{\circ}$ secciones según se describe en el esquema $n^{\circ} 1$.

b) Se procedió al estudio del árbol coronario mediante la realización de cortes transversales cada $5 \mathrm{~mm}$ a lo largo de toda su longitud. Las coronarias calcificadas fueron fijadas y decalcificadas en ácido nítrico al $10 \%$ antes de su estudio microscópico.

c) A continuación se procedió a la apertura y estudio de las cavidades cardíacas, para lo cual se abrieron sucesivamente siguiendo el mismo orden que la circulación sanguínea.

El tallado de las muestras se hizo en fresco y a continuación se procedió a su fijación. En todos los casos se prepararon bloques tisulares con fragmentos de $2 \times 1 \times 0.5 \mathrm{~cm}$ aproximadamente de miocardio. Los bloques fueron hechos incluyendo todo el espesor de la pared cardíaca. De cada corazón fueron extraídos un total de nueve secciones correspondientes a: Ventrículo derecho (una sección de la pared externa del tercio medio), Ventrículo izquierdo (una sección de la pared anterior del tercio superior, una sección de la pared lateral del tercio superior, una sección de la pared posterior del tercio superior, una sección de la pared anterior del tercio medio, una sección de la pared lateral del tercio medio, una sección de la pared posterior del tercio medio, una sección de la porción anterior del ápex y otra sección de la porción posterior del ápex, según el esquema $n^{\circ} 2$.

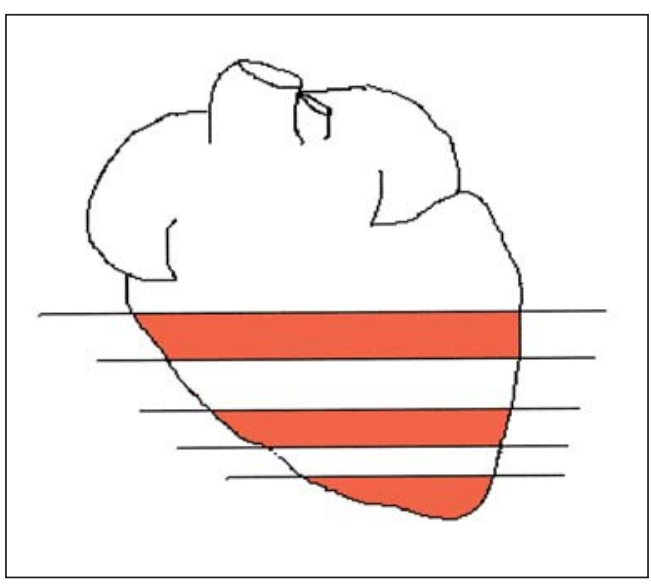

Esquema $n^{\circ} 1$

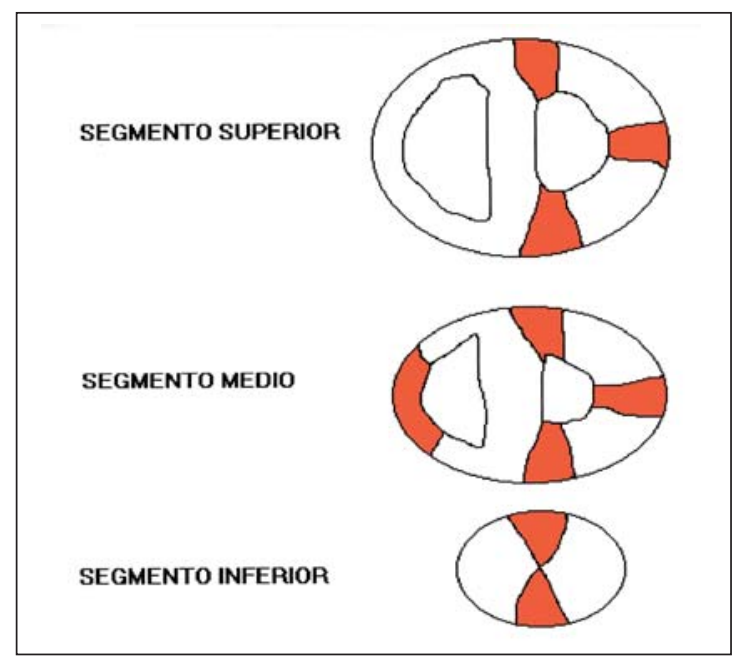

Esquema $n^{\circ} 2$ 
Además de las secciones descritas, la obtención de muestras se completó con otras procedentes de los principales troncos coronarios para valorar microscópicamente el grado de obstrucción así como la confirmación histológica de trombosis coronaria en aquellos casos de sospecha macroscópica.

Por razones metodológicas, decidimos clasificar todos los casos en 5 grupos:

Grupo I: Con infarto macroscópico (controles positivos), $(n=6)$.

Grupo 2: Con trombosis coronaria y sin infarto $(n=14)$.

Grupo 3: Con arteriosclerosis coronaria importante (con un grado de obstrucción igual o superior al 50\%), $(n=28)$.

Grupo 4: Sin trombosis ni arteriosclerosis (con un grado de obstrucción igual o inferior al $50 \%),(n=8)$.

Grupo 5: Muertes rápidas de etiología no cardíaca (controles negativos), $(n=8)$.

\section{c) Preparación de bloques tisulares:}

Las muestras extraídas se fijaron en formol tamponado al 4\% durante un periodo máximo de 24 horas. Las muestras de cada una de las secciones de tejido fueron separadas y etiquetadas según la nomenclatura indicada anteriormente. A continuación, se procesaron mediante un sistema automático (Shandom, Citadel 1000. England) e incluidas en parafina. El proceso de enfriamiento se realizo lentamente para conseguir una solidificación total, sin formación de burbujas; una vez enfriado el bloque, se desprendió del molde metálico y se procedió al corte.

La orientación del trabajo y la finalidad de este, justificó la realización de un promedio de veinticinco cortes de cada sección, destinados a la realización de las diferentes técnicas convencionales y al ensayo de los diferentes anticuerpos.

\section{D) TÉCNICAS HISTOLÓGICAS CONVENCIONALES:}

Se realizaron secciones de tejido de 4 micras, que fueron teñidas con hematoxilina-eosina y tricrómico de Masson para su estudio rutinario. A continuación se obtuvieron nuevas secciones de 5 micras para la realización de técnicas inmunohistoquímicas.

\section{e) Procedimiento inmunohistoquímico:}

Para el estudio inmunohistoquímico, se utilizaron diferentes anticuerpos de utilidad diagnóstica en patología quirúrgica. El ensayo se llevó a cabo mediante la técnica del complejo estreptavidina-biotina-peroxidasa, siendo utilizados los siguientes anticuerpos:

\begin{tabular}{|lll|}
\hline $\begin{array}{l}\text { Anticuerpo } \\
\text { ensayado }\end{array}$ & Origen / Laboratorio & Concentración \\
\hline Actina HHF-35 & Monoclonal. Enzo & $1: 50$ \\
\hline C5 b-9 & $\begin{array}{l}\text { Monoclonal, clon AE11. } \\
\text { Dako }\end{array}$ & $1: 25$ \\
\hline Desmina & $\begin{array}{l}\text { Monoclonal, clon D33. } \\
\text { Dako }\end{array}$ & $1: 50$ \\
\hline Mioglobina & Policlonal. Dako & $1: 5$ \\
\hline
\end{tabular}


La técnica inmunohistoquímica se realizó sobre cortes de parafina de 5 micras de espesor, que se recogieron en portas tratados con 3-aminopropiltrietoxisilano (Fluka, Buchs, Suiza) diluido al $2 \%$ en acetona. Los cortes se introdujeron en una estufa de secado a una temperatura de $50^{\circ}$ durante 24 horas. Tras desparafinarlos e hidratarlos se efectuaron los siguientes pasos:

I.- Desenmascaramiento antigénico por calor: Los cortes se trataron en tampón Citrato sódico $10 \mathrm{mM}$, pH 6, en microondas a $750 \mathrm{w}$. de potencia, haciendo primeramente dos pases de 5 minutos cada uno. Se retiran los cortes y se dejan enfriar en el mismo tampón a temperatura ambiente y durante 20 minutos.

2.- Dos lavados con PBS durante 5 minutos cada uno y se rodea la muestra con Dako Pen.

3.- Retirar el exceso de PBS.

4.- A partir de aquí se procedió a la incubación del anticuerpo primario con los siguientes pasos:

4. I .- Dilución en albúmina bovina (sigma) al 0, I \% en PBS de pH 7.5.

4.2.- Dilución del anticuerpo en la albúmina bovina anteriormente preparada.

4.3.- Incubación durante I hora a temperatura ambiente.

5.- Dos lavados con PBS a temperatura ambiente durante 5 minutos cada uno.

6.- Retirar el exceso de PBS.

7.- Anticuerpo biotinado: Incubación durante 30 minutos a temperatura ambiente: DUET (Dako), 1000 microlitros de PBS +10 microlitros de reactivo $C+15$ microlitros de NGS (Normal Goat Serum. Dako).

8.- Dos lavados con PBS a temperatura ambiente durante 5 minutos cada uno.

9.- Retirar el exceso de PBS

10.- Inhibición de la peroxidasa endógena con $\mathrm{H}_{2} \mathrm{O} 2$ al 3\% durante 10 minutos a temperatura ambiente.

I I.- Dos lavados con PBS a temperatura ambiente durante 5 minutos cada uno.

12.- Retirar el exceso de PBS.

13.- Complejo Streptavidina-Biotina-Peroxidasa: Incubación durante 30 minutos a temperatura ambiente: DUET (Dako), 1000 microlitros de PBS + 10 microlitros de reactivo A +10 microlitros de reactivo $B$.

14.- Dos lavados con PBS a temperatura ambiente durante 5 minutos cada uno.

15.- Retirar el exceso de PBS.

16.- Tinción con diaminobencidina durante 10 minutos.

Preparar la solución antes de ser utilizada, del modo siguiente: I tableta de DAB (Merck) + $10 \mathrm{ml}$ de agua destilada. Añadir 10 microlitros de $\mathrm{H} 2 \mathrm{O} 2$ al 3\%.

17.- Después de lavar en agua destilada durante 5 minutos, se contratiñó con hematoxilina de Harris durante 30 segundos.

18.- Lavado con agua destilada, deshidratación, aclarado y montaje.

En todos los casos estudiados se valoraron las características macro y microscópicas convencionales. Se valoró además el estado de los vasos intramiocárdicos (diabetes, hipertensión, enfermedad de las pequeñas arterias, etc).

Se valoró la positividad y negatividad de los distintos anticuerpos empleados. Para cuantificar los resultados obtenidos, se realizó un contaje semicuantitativo. Se consideraron positivos cuando afectaban a más del 20\% de las fibras en cada preparación. Se estableció el umbral del 20\% teniendo en cuenta los resultados de los controles negativos. El contaje se realizó a 400 aumentos por dos observadores y todos los resultados fueron revisados al cabo de otros 3 meses. 


\section{RESULTADOS Y DISCUSIÓN:}

Los resultados de los diferentes anticuerpos ensayados en este estudio, son expuestos en las tablas I a VI.

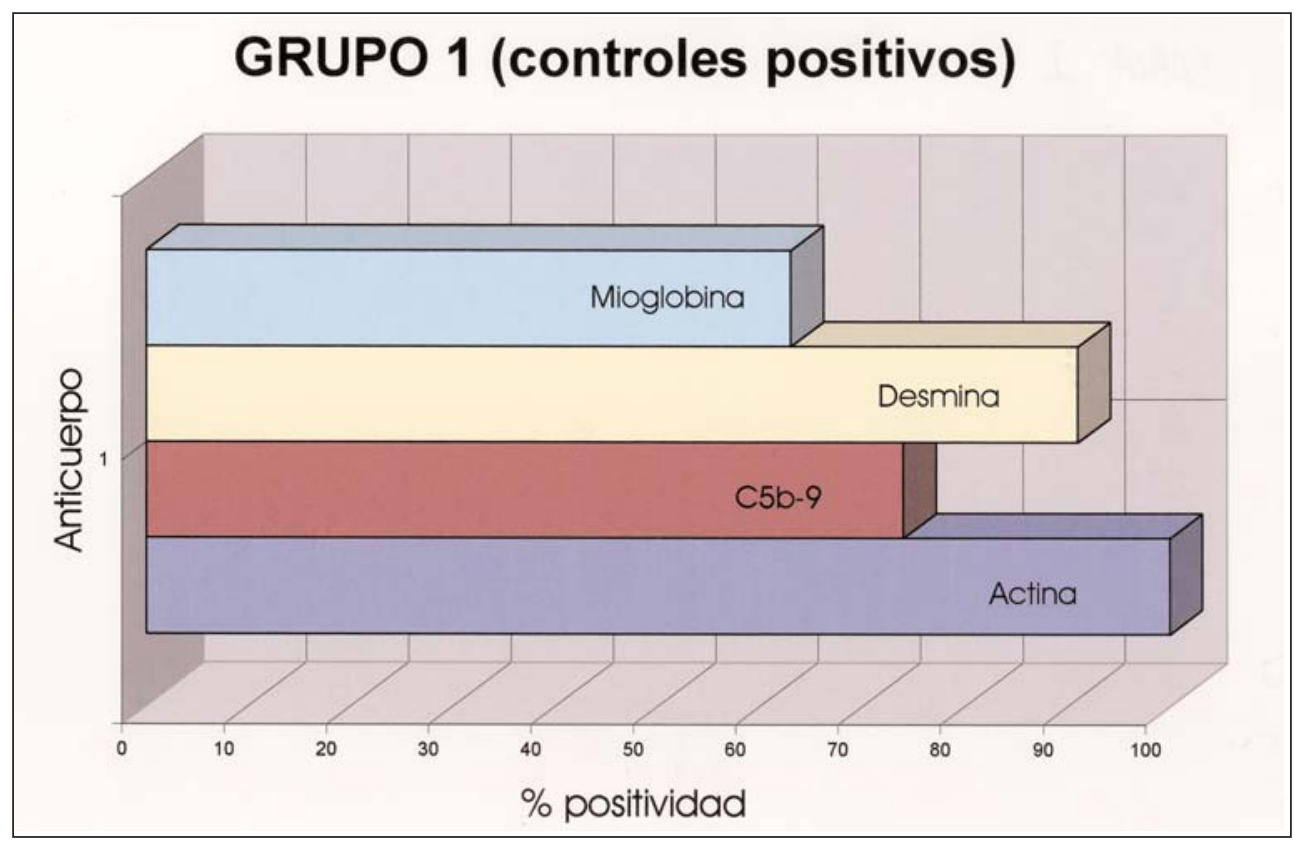

Tabla I.- Resultados en el grupo control positivo.

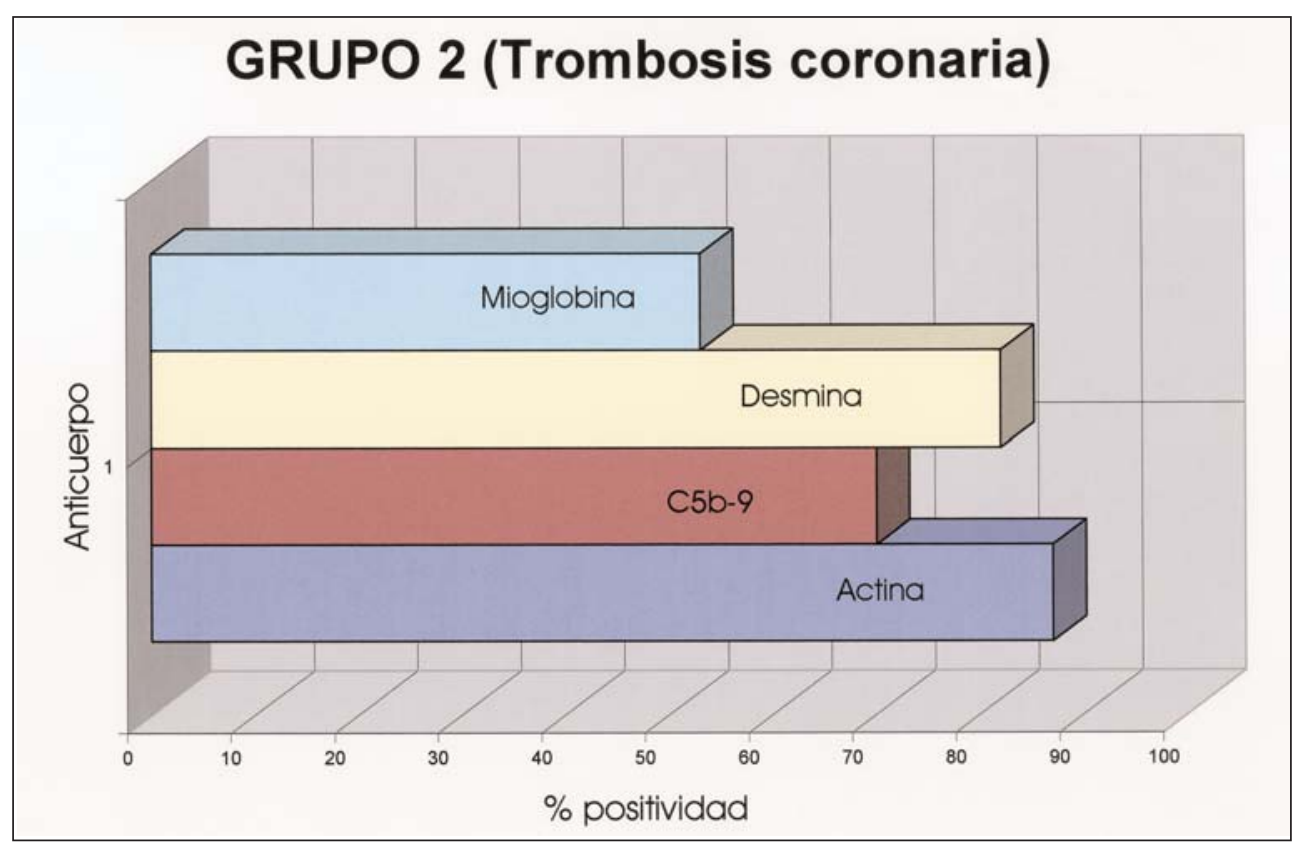

Tabla II.- Resultados en el grupo de casos con trombosis coronaria. 


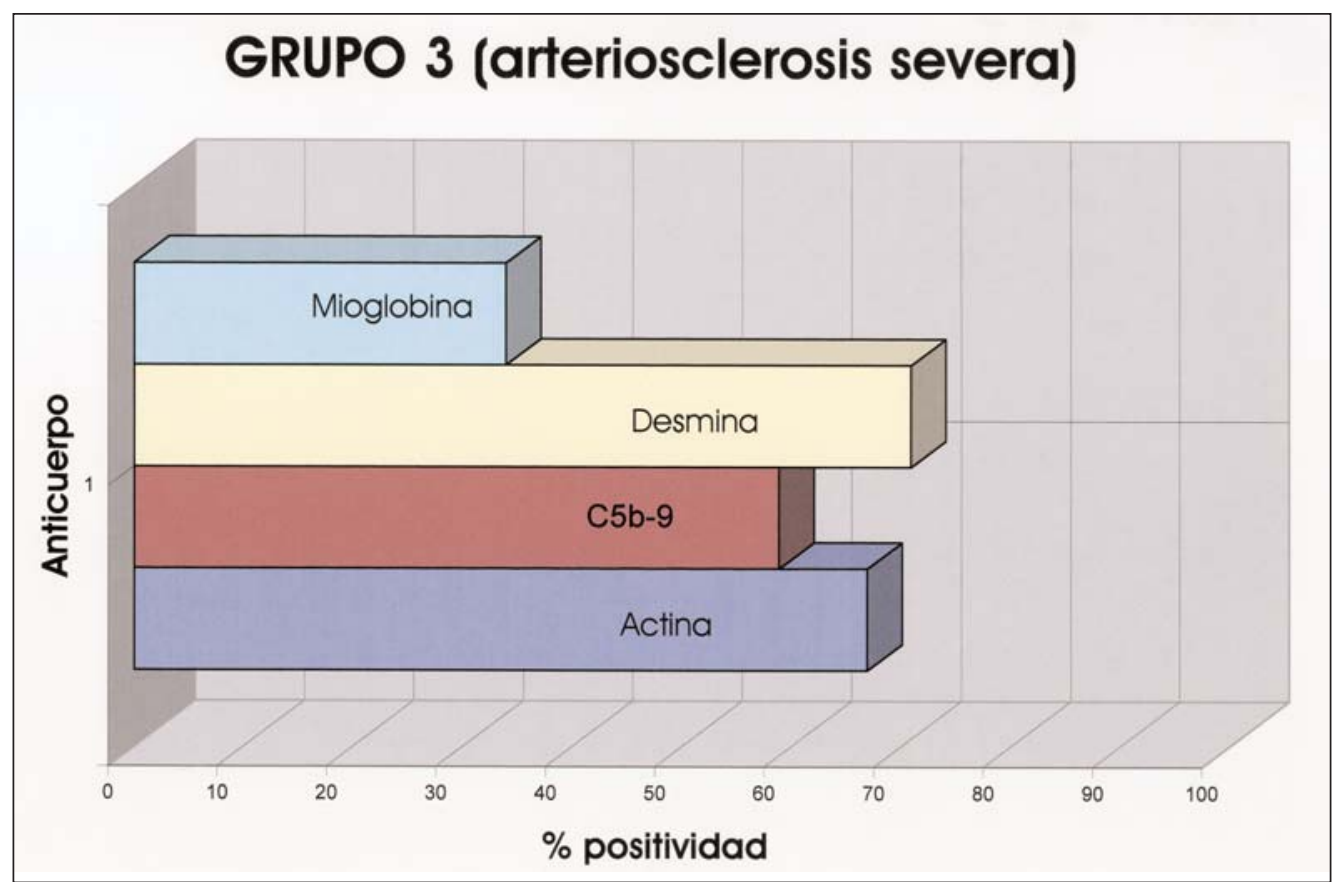

Tabla III.- Resultados en el grupo con lesión arteriosclerótica importante.

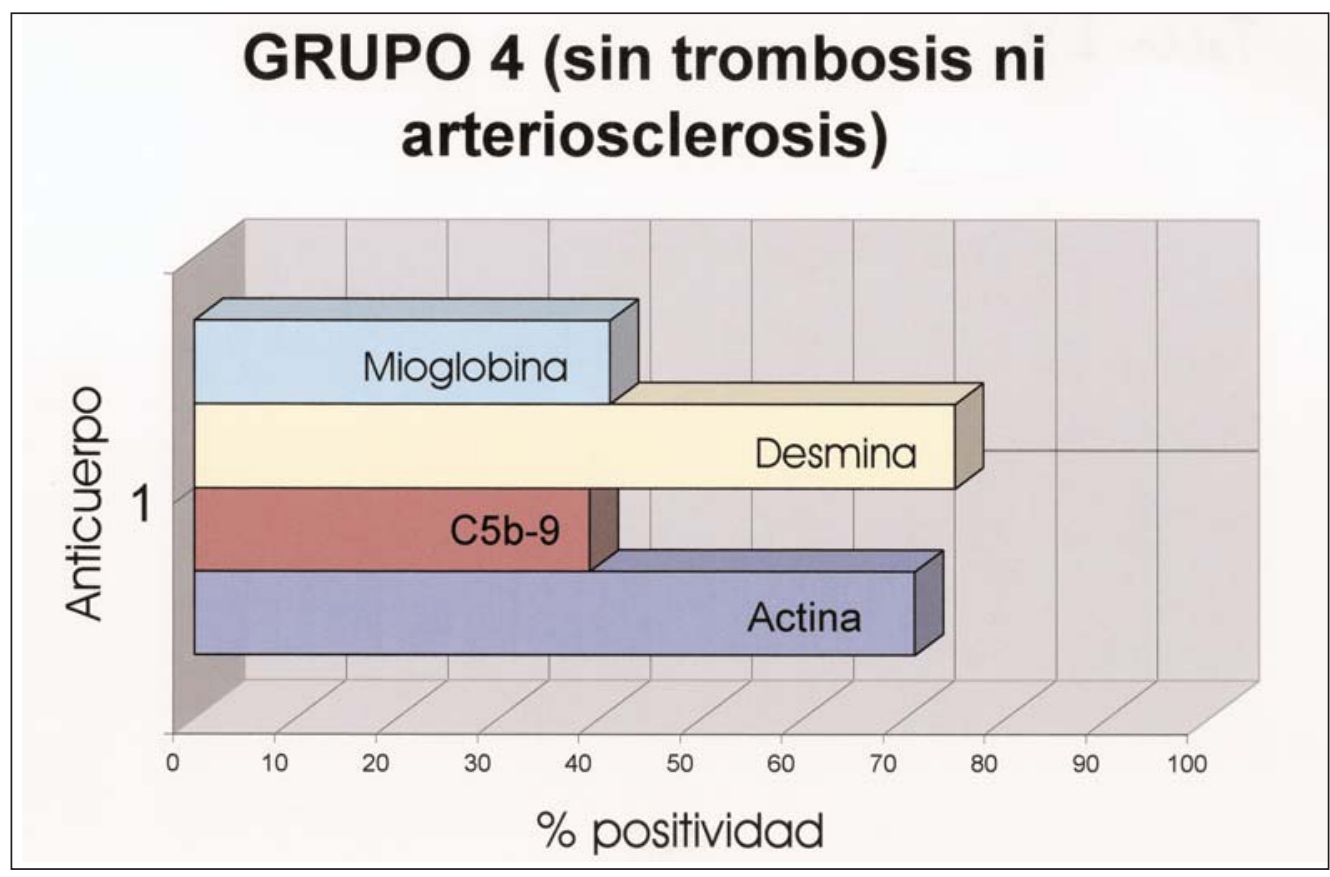

Tabla IV.- Positividad para los diferentes anticuerpos en el grupo de casos sin lesiones anatomopatológicas relevantes. 


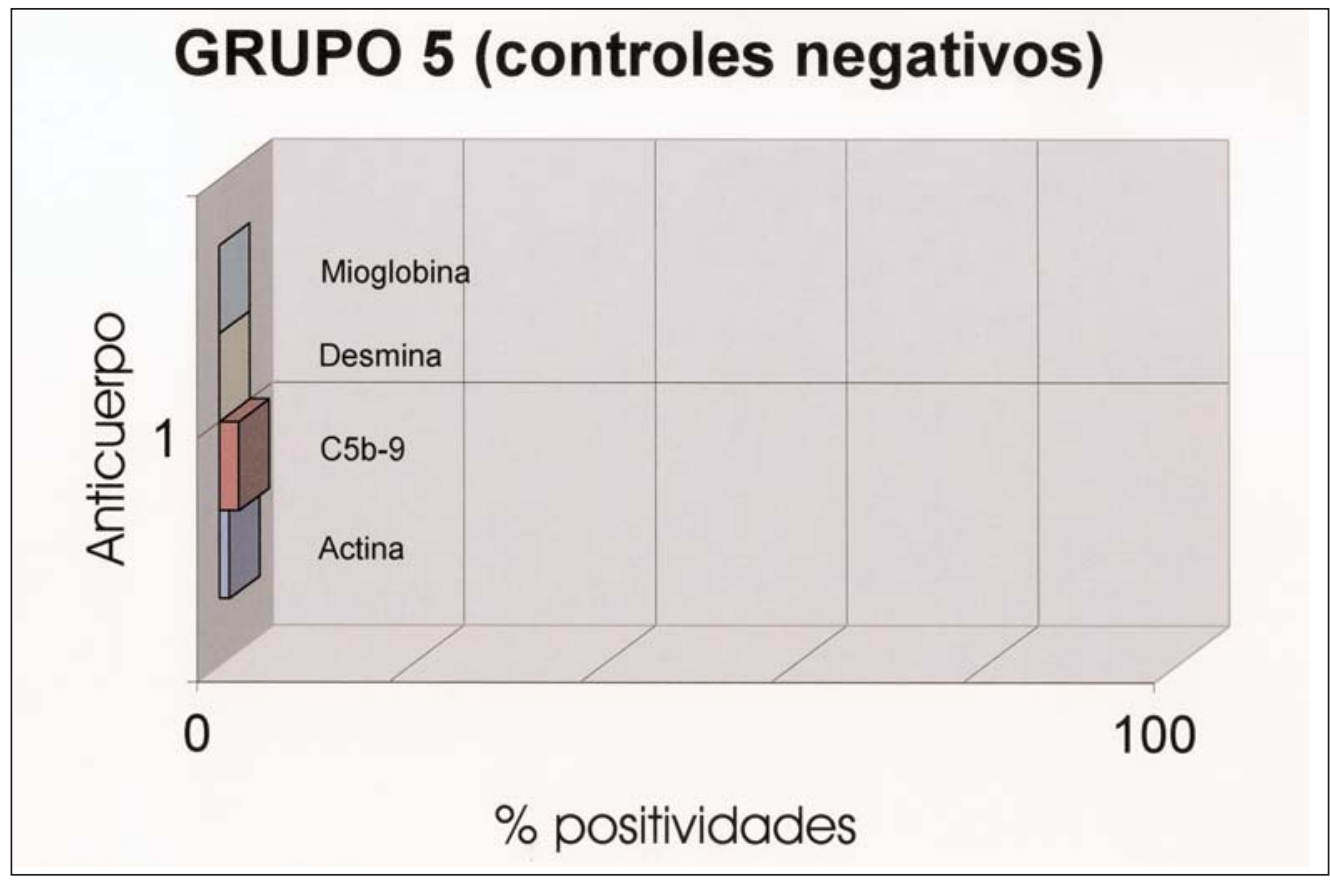

Tabla V.- Positividades en el grupo de muertes instantáneas o muy rápidas (controles negativos).

\begin{tabular}{|l|c|c|c|c|c|}
\hline Anticuerpo & $\begin{array}{c}\text { Control } \\
+\end{array}$ & Trombosis & Arteriosclerosis & $\begin{array}{l}\text { Sin trombosis } \\
\text { ni arteriosclerosis }\end{array}$ & $\begin{array}{c}\text { Control } \\
\text { Actina }\end{array}$ \\
\hline 100\% & $87 \%$ & $67 \%$ & $71 \%$ & $12.5 \%$ \\
\hline C5b-9 & $74 \%$ & $70 \%$ & $59 \%$ & $39 \%$ & $25 \%$ \\
\hline Desmina & $91 \%$ & $82 \%$ & $71 \%$ & $75 \%$ & $0 \%$ \\
\hline Mioglobina & $63 \%$ & $53 \%$ & $34 \%$ & $41 \%$ & $0 \%$ \\
\hline & & & & & \\
\hline
\end{tabular}

Tabla VI.- Correlación entre los resultados globales de los diferentes anticuerpos y los grupos de casos.

Inicialmente conviene señalar que el trabajo que se ha realizado, ha tenido un planteamiento esencialmente prospectivo. Durante su desarrollo, se han podido comprobar dos tipos de dificultades: por una parte, la llamativa escasez de autopsias médicolegales con documentación anatomopatológica, que pudieran ser útiles para los objetivos propuestos. En nuestro país, y más en concreto en nuestro medio, la mayoría de las autopsias médicolegales que se practican, no cuentan con el apoyo importante de este tipo de exámenes complementarios [34]; así el diagnóstico postmortem del infarto de miocardio se ve reducido a un nivel macroscópico, muchas veces inferido de otro tipo de lesiones presentes en el cadáver (p. ej. un grado considerable de arteriosclerosis coronaria) o basado exclusivamente en la sintomatología previa al fallecimiento y relatada de forma inexacta y errónea por los testigos, sin que exista una verdadera correlación anatomopatológica [35]. 


\section{UTILIDAD DE LOS MARCADORES INMUNOHISTOQUÍMICOS:}

La aplicación de procedimientos inmunohistoquímicos al diagnóstico de la isquemia miocárdica en fases precoces surgió en la década de los 70, configurándose rápidamente como un método selectivo y más resolutivo que la histología convencional. Entre las ventajas que representa, respecto a otras técnicas de empleo en los laboratorios de Histopatología forense, está su alto grado de especificidad y sensibilidad, así como su relativa sencillez de ejecución [36].

Consideramos que la utilización de un panel de anticuerpos de uso habitual puede ser de gran utilidad en el acercamiento diagnóstico de este tipo de patología (infarto). Fueron seleccionados fundamentalmente los marcadores inmunohistoquímicos dado que pensamos que el hecho de exigir otros procedimientos técnicos que no están habitualmente incorporados a la rutina de los laboratorios de histopatología, y que como tal, no son dominados por el forense, puede dificultar la tarea del estudio. Un hecho importante en la utilización de la inmunohistoquímica, y que debe tenerse presente, es la posibilidad de comparar resultados de muestras procesadas con diferentes tinciones o anticuerpos.

Diversos estudios resaltaron el valor de las proteínas estructurales (actina, desmina, mioglobina, etc.), como marcadores de utilidad reconocida, pero extremadamente variable para el diagnóstico inmunohistoquímico del infarto de miocardio. La variabilidad de las cifras registradas por los diferentes autores, reflejan probablemente las grandes diferencias en la selección de los casos estudiados, especialmente en lo referente al tiempo de evolución de los infartos. En general, estas publicaciones especializadas contienen casos de infarto de miocardio de larga evolución.

Con el objetivo de evaluar la eficacia de las técnicas fueron recogidos 6 casos de infartos de miocardio, macroscópicamente reconocibles, dos de los cuales, tenían un soporte clínico (registro electrocardiográfico y elevación de enzimas cardíacos en sangre). Dado que todos estos casos (controles positivos) mostraron un incremento de la inmunoreactividad para C5-b9 y disminución de la misma para desmina, mioglobina y actina, la sensibilidad de las técnicas fue aceptable.

Para el grupo de controles negativos fueron seleccionados 16 individuos con muerte rápida de etiología no cardíaca, especialmente víctimas de traumatismos cráneoencefálicos en accidentes de tráfico, precipitaciones, heridas por arma de fuego, etc. Se partió de la base de considerar que cuando una muerte tiene lugar de forma instantánea o casi instantánea, los cambios hipóxicos agonales de la fibra cardíaca no existen o bien son mínimos, constituyendo un buen control negativo. La hipótesis precedente se vio confirmada durante la realización del estudio, comprobando como mayoritariamente dichos controles no presentaban inmunoreactividad. Únicamente dos casos presentaron positividad para algún anticuerpo (uno de ellos fue positivo para actina y (5b-9). Tras la repetición de las técnicas en dichos casos, obtuvimos el mismo resultado. No pudimos ofrecer una explicación plenamente satisfactoria de dicho comportamiento, no obstante consideramos que este dato aislado podía obedecer al hecho de que la muerte no hubiese sido tan rápida como pensábamos y a la existencia de una cierta agonía que indujese cambios hipóxicos en la fibra muscular cardíaca. La especificidad de la técnica resultó así aceptable desde el punto de vista metodológico.

\section{CONSIDERACIONES TÉCNICAS:}

Uno de los aspectos más críticos respecto al procesado de las muestras durante la autopsia es quizás, el tiempo de fijación y la elección del líquido fijador. La fijación óptima depende básicamente del tipo de fijador, y del tipo de técnica que se piensa utilizar [37, 38]. 
Hay que admitir el hecho de que no existen fijadores óptimos para todo tipo de antígenos, dado que muchos de ellos pueden desnaturalizarlos o alterar la cadena polipeptídica enmascarando el epitopo a determinar. En nuestro estudio, los resultados más satisfactorios, los hemos obtenido utilizando formol tamponado al 10\%.

En lo que respecta a la metodología seguida, conviene señalar que la mayoría de las muestras precisaron como máximo 24 horas de fijación para poder llevar a cabo las técnicas elegidas, a pesar de que algunos autores consideran que el tiempo de fijación es irrelevante para la inmunoreactividad de anticuerpos como el C5b-9 [I I]. Únicamente en un pequeño porcentaje de casos, y tras haber observado defectos de fijación con las técnicas convencionales (Hematoxilina-eosina, tricrómico de Masson), fue necesaria su prolongación hasta las 36 horas.

Durante la técnica se pudo observar que la utilización de enzimas proteolíticos disminuía la sensibilidad del método inmunohistoquímico para los anticuerpos ensayados en este estudio. Por este motivo se optó por la incubación de los cortes histológicos mediante microondas.

La mezcla de los anticuerpos con glicerol a partes iguales, comportó la ventaja de poder disponer de cantidades suficientes de anticuerpo en cualquier momento sin la necesidad de congelarlo y descongelarlo, lo que permitió una mejor disponibilidad del mismo durante varios años.

Dentro de los diferentes criterios que pueden ser fijados en función de las condiciones particulares de selección de casos o de recogida de muestras, uno de los más importantes es sin duda la resolución con que fueron examinados (los observadores). Para una correcta interpretación de los hallazgos, se efectuaron evaluaciones separadas de cada caso, siendo revisados al cabo de tres meses viendo la correlación entre la primera y la segunda valoración de las muestras. El resultado final fue consensuado entre ambos observadores. En términos generales, se puede afirmar que los resultados fueron obtenidos en condiciones basales siempre iguales o muy similares para cada anticuerpo y cada muestra.

\section{INTERPRETACIÓN DE LOS RESULTADOS:}

La interpretación de los resultados puede constituir uno de los aspectos más difíciles de la inmunohistoquímica y debe ser llevada a cabo con suma precaución, flexibilidad y siendo conocedores de los errores que, potencialmente, pueden presentarse. En nuestra opinión, resulta de suma importancia estar familiarizado con los diferentes patrones de tinción y con el grado de sensibilidad y especificidad de los distintos anticuerpos utilizados durante el estudio, para una correcta valoración de los resultados.

En general, una tinción positiva es más fiable y valorable que una negativa. Además, ha de tenerse en cuenta la aparición de falsos positivos o negativos, debidos generalmente a problemas técnicos o de la fijación de las muestras.

Para realizar el presente estudio y la comparación de los diferentes resultados se han seleccionado los parámetros cuya alteración consideramos que tienen mayor trascendencia: infarto macroscópico, arteriosclerosis y trombosis coronaria, dado que constituyen diagnósticos manejados habitualmente por la mayoría de los médicos forenses. La mayor parte del resto de los parámetros, consideramos que no son apreciables salvo mediante examen microscópico.

En numerosos casos se ha podido comprobar que las técnicas histológicas convencionales no ofrecían hallazgos típicos de isquemia irreversible (Fig. I), probablemente por la rapidez de la muerte [39]. Esto impide que el diagnóstico histológico sea concluyente, siendo necesaria la utilización de técnicas más específicas. 


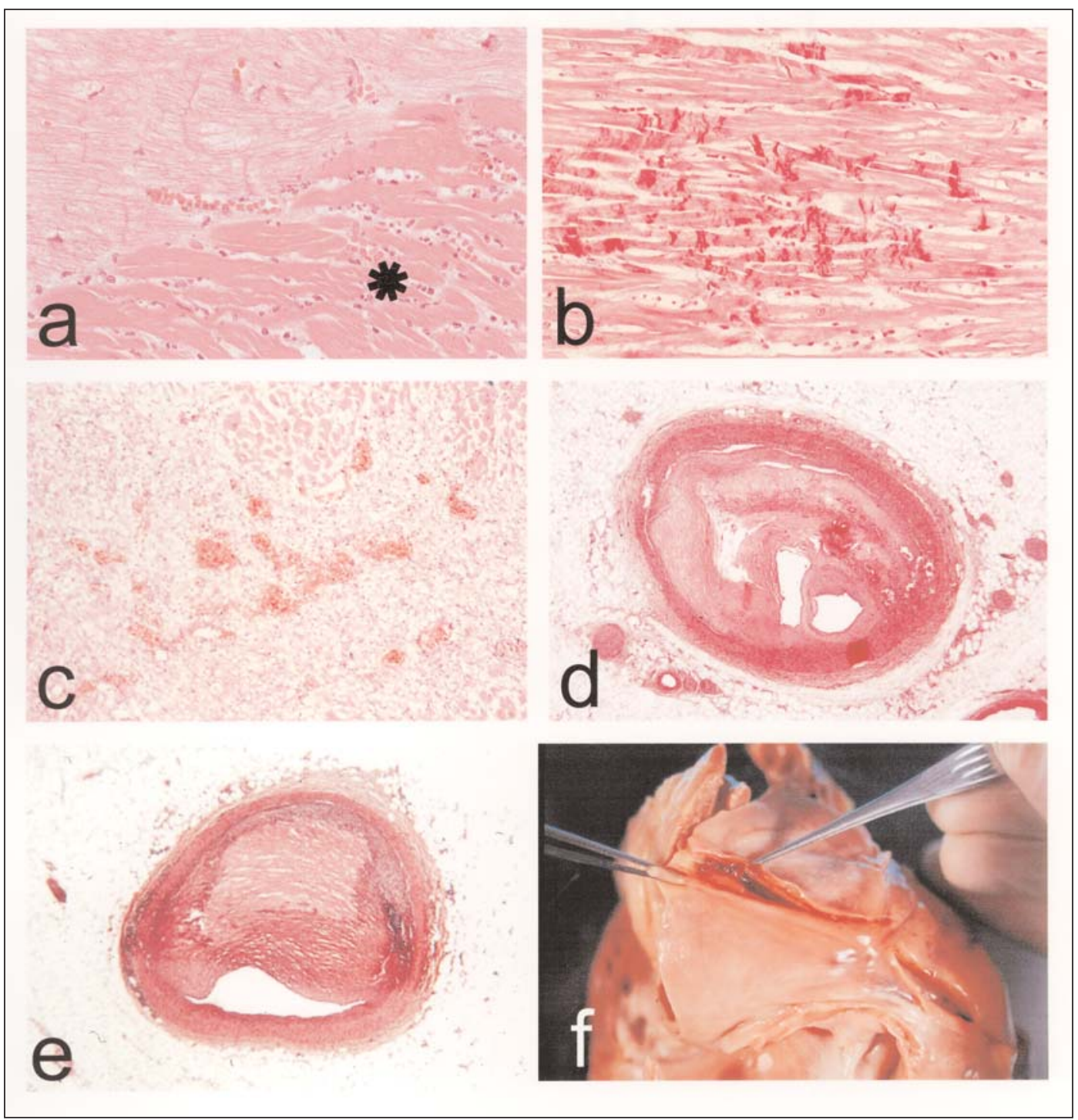

Fig. 1.- a) Necrosis de coagulación en fibras cardíacas isquémicas (asterisco, H\&E, 40x). b) Necrosis en forma de bandas de contracción (H\&E, 40x). c) Formación de neovasos en una zona de tejido colágeno (cicatriz miocárdica postinfarto) (H\&E, 20x). d) Trombo coronario oclusivo recanalizado (H\&E, 4x). e) Placa coronaria fibrocalcificada con reducción de un $80 \%$ de la luz vascular (H\&E, 4x). f) Aspecto macroscópico de un trombo coronario adherido a la íntima de la circunfleja izquierda.

Resultados de La inmunohistoquímica (Figs. 2 y 3).

a) C5b-9

Se observaron tinciones intensamente positivas en las áreas de infarto correspondientes a los controles positivos. Por su parte en los casos problema se comprobó una buena tinción de necrosis unicelular en las zonas afectadas, así como de tinción perimembranosa e intersticial en las áreas periféricas y próximas a la zona de isquemia. Estos resultados concuerdan básicamente con los expresados por Schäfer y cols [2I]. 


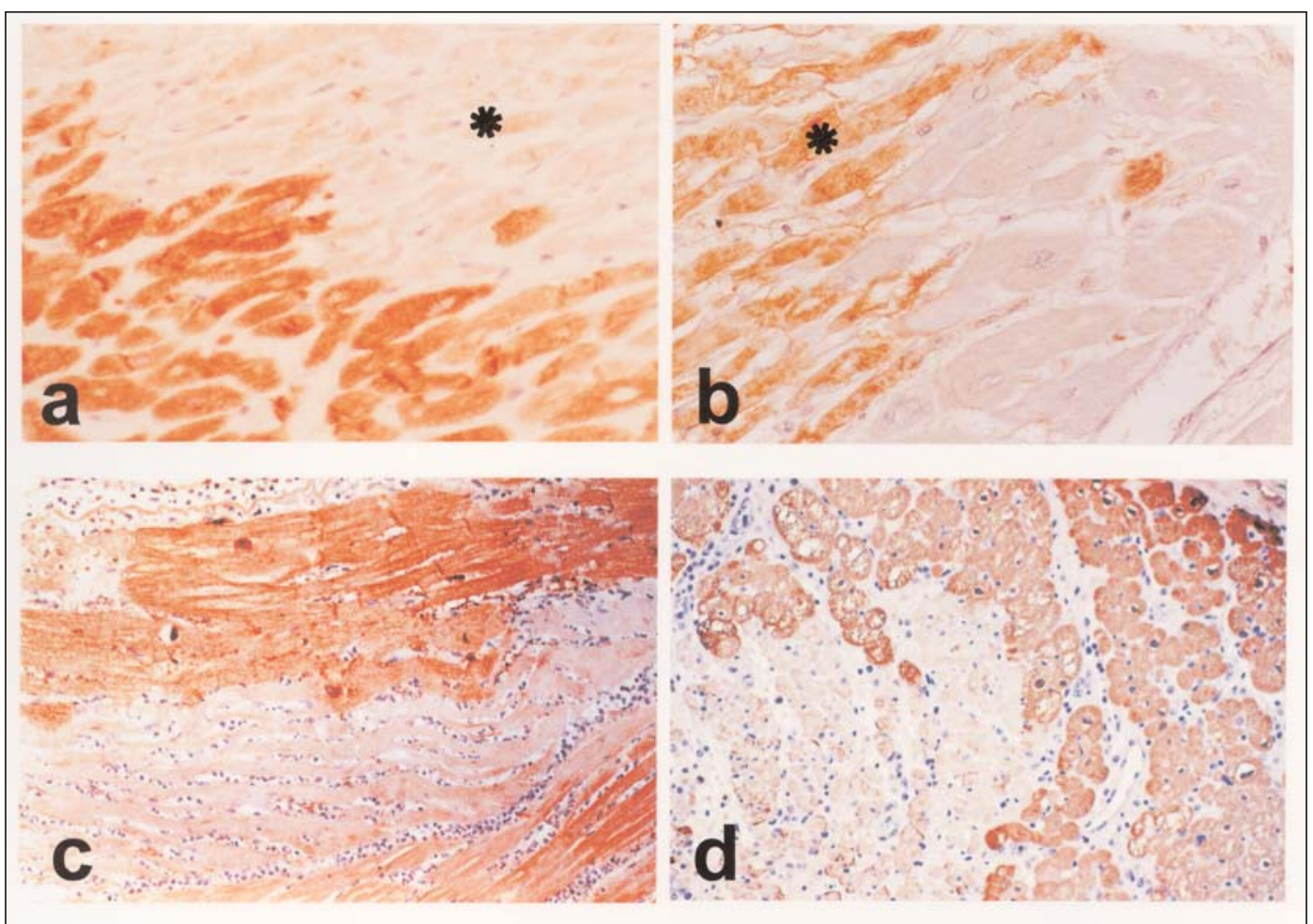

Fig. 2.- a) Depleción de desmina en miofibrillas isquémicas (asterisco). b) Inmunotinción positiva para C5b-9 (asterisco). c) Pérdida de positividad para actina en miocardio infartado con presencia de infiltrado polimorfonuclear (mitad inferior de la preparación). d) Positividad para mioglobina en la zona de miocardio intacto (superior derecha) en contraste con la zona isquémica (inferior izquierda).

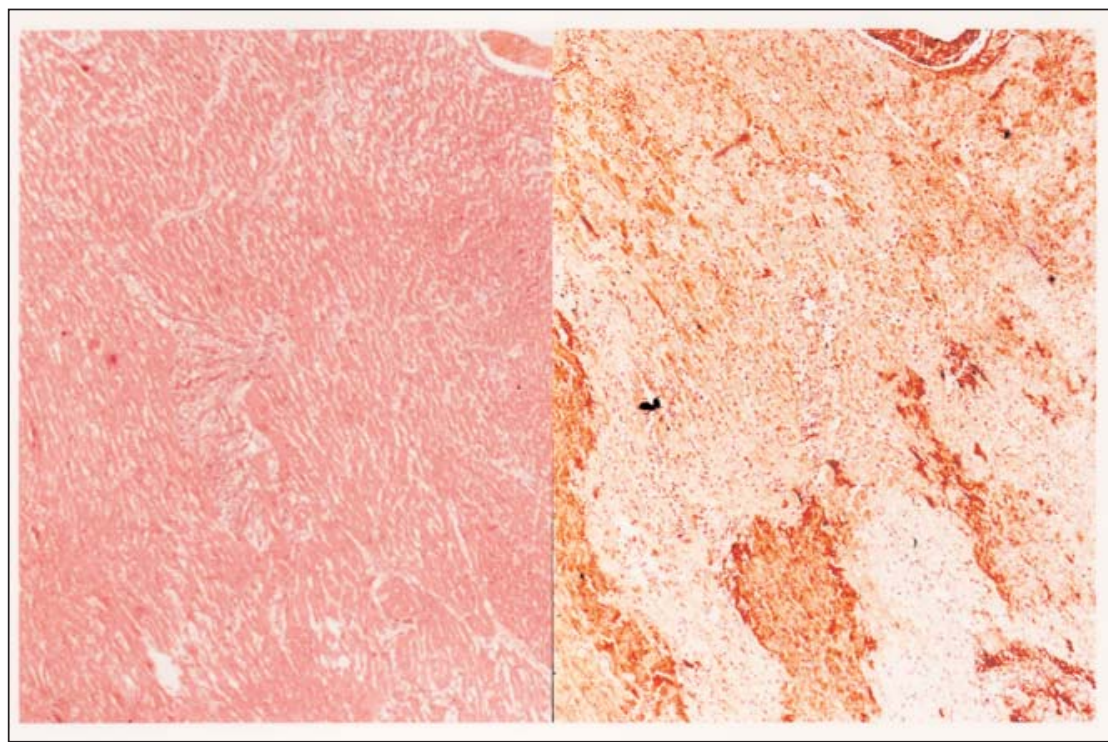

Fig. 3.- Cortes seriados: ausencia de datos histológicos de isquemia con hematoxilina-eosina en contraste con la intensa positividad para C5b-9 (10x). 
Este anticuerpo se acumula inicialmente y de forma específica, en la superficie de las células dañadas. La tinción observada era exclusivamente de membrana. No obstante, cuando el período de isquemia es sostenido, la inmunotinción afecta también al citoplasma, tal vez debido a que el daño celular se ha hecho tan extenso que ha permitido la apertura de poros de membrana facilitando así su paso a través de la misma. No se observó positividad nuclear.

La positividad observada en áreas subendoteliales de los vasos, no parece guardar correlación con la existencia de isquemia miocárdica sino más bien con la edad y el desarrollo de arteriosclerosis [40]. En el presente estudio, la presencia de inmunotinción positiva en el endotelio vascular, se utilizó como elemento de control positivo para la técnica.

El promedio de positividad alcanzó solamente algo más de la mitad de los casos problema. En un porcentaje importante (44\%), la tinción fue negativa. Se trataba de muertes ocurridas en un corto intervalo de tiempo entre la presentación de los síntomas y el fallecimiento. Al respecto, el interesante estudio de Thomsen [28] confirma estos datos y consideran que la lesión es evidenciable únicamente si el tiempo de isquemia es superior a 40 minutos. El anticuerpo se reveló más efectivo en los casos que presentaban trombosis coronaria sobreañadida.

\section{b) Desmina:}

El hallazgo más ampliamente observado con este anticuerpo fue la disminución o pérdida de esta proteína en las áreas de miocardio isquémico. El efecto de la isquemia sobre esta proteína fue menor en las regiones subendocárdicas, probablemente por el aporte suplementario de sangre que supone el contacto de esta zona del miocardio con las cavidades. En ocasiones resultaba difícil diferenciar una zona indemne de otra constituida por la red de Purkinje, que posee una morfología bastante similar.

Las primeras estructuras intracitoplasmáticas afectadas eran las estriaciones transversales, mientras que cuando el infarto era mucho más evolucionado (controles positivos) la afectación incluía toda miofibrilla.

La mayor tasa de positividades dentro del grupo problema, se dio en el grupo de las trombosis, sin embargo no se observaron diferencias significativas respecto a los otos grupos, manteniéndose una cierta uniformidad en su comportamiento.

\section{c) Mioglobina:}

En las zonas isquémicas se produjo fundamentalmente una pérdida de mioglobina. Curiosamente las áreas de tejido que mostraban depleción de esta proteína, resultaban positivas para el C5b-9. En cualquier caso, las fibras que presentaban disminución de la inmunotinción no mostraban alteraciones morfológicas típicas y sugestivas de isquemia tales como bandas de contracción intracitoplasmática, cariorrexis o cariolisis, o fucsinorragia.

Al igual que los demás anticuerpos, este mostró una mayor sensibilidad en el grupo de casos con trombosis coronaria.

\section{d) Actina:}

Hemos podido comprobar como en períodos muy cortos de isquemia ( I hora aproximadamente) se producía una disminución de la inmunoreactividad en aquellas fibras afectadas por la isquemia y/o necrosis. Este hallazgo, coincide básicamente con los estudios previos de Nishida y cols [2], quien observaron como el anticuerpo anti-actina desaparecía en el lugar del infarto, mientras que la microscopía electrónica demostraba la existencia de esta proteína en la fibra muscular cardíaca. 
Este comportamiento sugiere que la isquemia induce algunos cambios bioquímicos a nivel molecular de la actina, además de cambios estrictamente estructurales o morfológicos. Los anticuerpos para actina y desmina se han mostrado como los más efectivos.

\section{INMUNOHISTOQUímICA EN CASOS DE AUTOLISIS:}

Sobre esta cuestión existe un alto grado de controversia: algunos autores señalan buena tolerancia a la autolisis [20] y otros indican que cuando existe autolisis, a medida que aumenta el intervalo postmortem, disminuye la positividad de las técnicas [10]. Nuestro material no ha estado sometido a ningún grado de autolisis, por lo tanto no hemos tenido ocasión de ensayar las técnicas
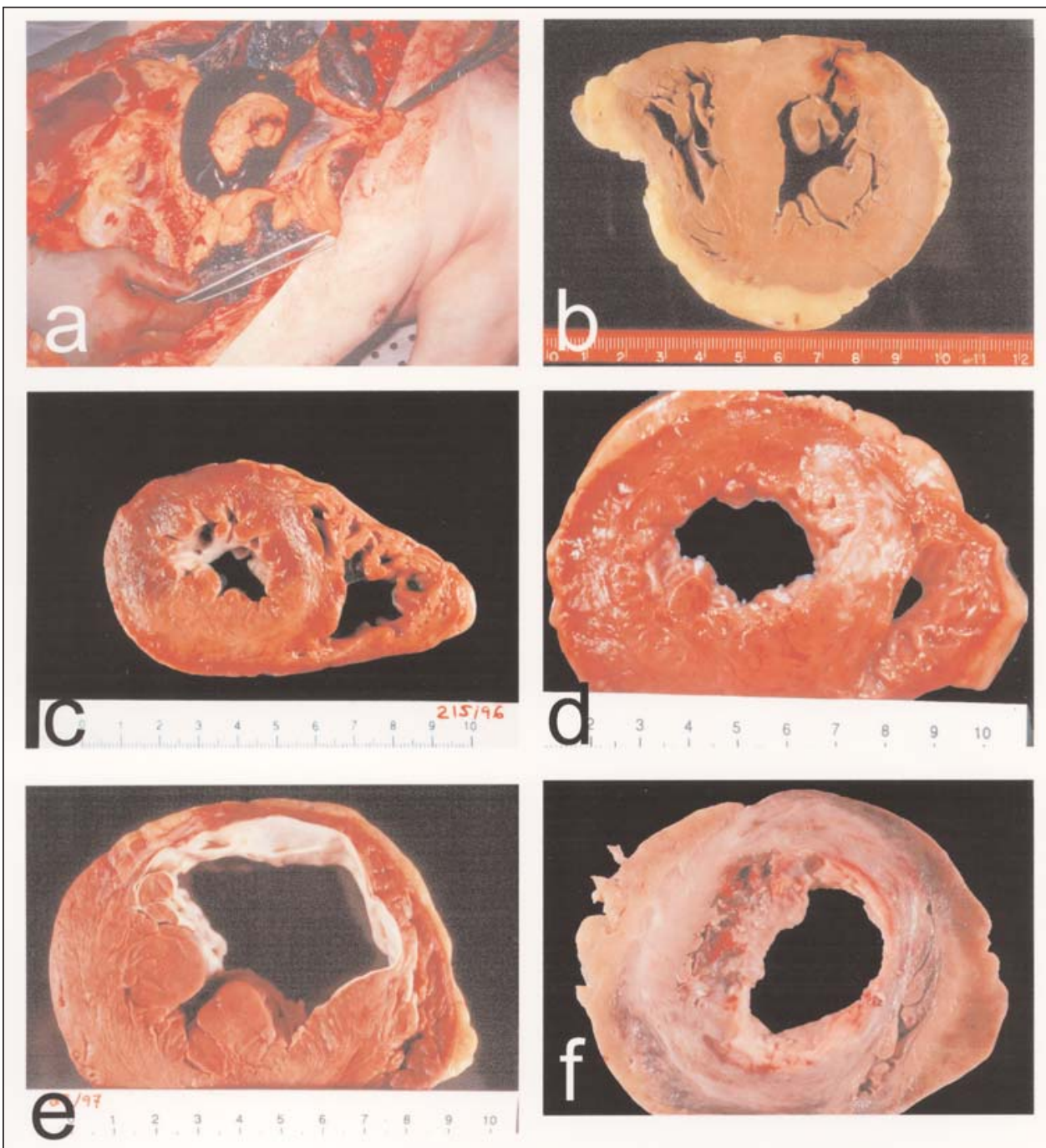

Fig. 4.- a) Hemopericardio por rotura del ventrículo izquierdo en el curso de un infarto de miocardio. b) Infarto transmural que afecta al muro posterior del V.I. c) Isquemia reciente de la pared posterior del ventrículo izquierdo. d) Cicatriz de aspecto nacarado (fibrosis) correspondiente a una lesión isquémica focal. e) Infarto antiguo subendocárdico circunscrito a la cara anterior del V.I. con adelgazamiento de la pared. f) Infarto subendocárdico circunferencial completo del V.I. con trombo fibrinohemático adherido al endocardio. 
en estas condiciones. No obstante, nuestros resultados coinciden básicamente con los de Ortman y cols [I I], que observa como determinados factores como el intervalo postmortem no parece tener ningún significado ni poseen un valor predictivo respecto a los resultados globales de la inmunohistoquímica.

\section{CASOS SIN haLlazgos:}

A partir de varias horas de isquemia, los cambios histológicos de lesión miocárdica pueden hacerse evidentes $y$, junto con las técnicas inmunohistoquímicas, permiten en la mayoría de los casos una evaluación segura del infarto de miocardio. Sin embargo, esto no siempre sucede así, en especial cuando el período de isquemia es muy breve.

Parece claro que cuanto más corta sea la duración de los síntomas, incluyendo aquellos fallecimientos instantáneos, menos probabilidades habrá de desarrollar lesiones morfológicas evidenciables (Fig. 4), y aun de detectarlas mediante las técnicas histopatológicas habituales, pues es conocida la posibilidad del desarrollo de una rápida arritmia, imposible de demostrar durante la autopsia.

En el estudio, nos ha llamado poderosamente la atención la presencia de un número importante de casos negativos. La tasa de negatividad con las técnicas convencionales, e incluso con estos marcadores inmunohistoquímicos ascendió al 22\% de los casos. Esta alta cifra puede obedecer a la existencia de un proceso básicamente de tipo funcional, sin que se haya establecido una verdadera lesión necrótica de la fibra miocárdica. La información obtenida de amplios estudios necrópsicos indica que el elevado índice de lesiones coronarias ulceradas, la ausencia de obstrucción trombótica completa y la presencia de microémbolos con puntos de microinfartos marcan una relación entre estas condiciones anatomopatológicas y la muerte súbita cardíaca en ausencia de evidencia de necrosis miocárdica reciente [4I, 42]. En estas situaciones parece razonable atribuir la muerte a una arritmia fatal de instauración brusca [43].

Dichos casos se correlacionan bastante bien con la presencia de numerosos focos de fibrosis intramiocárdica, expresados en nuestro estudio como focos de fibrosis intramiocárdica con un diámetro superior a $\mathrm{l} \mathrm{cm}$. Una explicación satisfactoria para estos casos la encontraríamos en el hecho bien demostrado, de que las cicatrices miocárdicas por infarto antiguo también pueden ser causa de taquicardias por reentrada y desencadenar una muerte súbita [44].

En relación con lo anterior, cabe señalar que cuando existe una cardiopatía isquémica crónica, el 35\% de los insultos isquémicos agudos pueden dar lugar a arritmias ventriculares fatales [45] y este incremento de la actividad ectópica ventricular tiene lugar fundamentalmente durante la última fase del episodio isquémico, cuando el segmento ST comienza a retornar a la línea isoeléctrica. La duración del episodio isquémico no parece influir en el incremento de la actividad ectópica ventricular.

La relación de causalidad entre la necrosis miocárdica y el desarrollo de arrítmias cardíacas y muerte súbita ha quedado patente en diferentes estudios fisiopatológicos y electrocardiográficos. Las alteraciones del ritmo cardíaco como reacción a la isquemia son conocidas desde hace tiempo, desde que se indujeron episodios de fibrilación ventricular con la simple presión digital del corazón. Los efectos electrofisiológicos celulares de la isquemia han quedado también demostrados en otros estudios clínicos y experimentales bien controlados [46]. Cuando se ocluye una arteria coronaria y comienza el infarto de miocardio, se han descrito una amplia variedad de actividades ectópicas, en su mayoría complejos ventriculares prematuros $[47,48]$, mientras que la taquicardia ventricular puede observarse en el I al $7 \%$ de los casos $[49,50]$, siendo esta generalmente de escasa trascen- 
dencia. La opinión es refrendada por Cheema y cols [5 I] únicamente cuando la taquicardia ventricular tiene lugar dentro de las siete primeras horas desde la presentación; si aparece más tardíamente el riesgo de muerte súbita se incrementa notablemente. Un reciente estudio experimental confirma que la isquemia aguda facilita la iniciación de fibrilación ventricular [52].

Por su parte Pepine y cols [53], así como Goldstein y cols [54] encuentran en I/3 de los pacientes datos de isquemia precediendo a la muerte súbita. A pesar de la evidencia de los estudios experimentales que establecen una firme relación entre isquemia y arritmia, no obstante en el terreno clínico esta relación es menos directa dado que es difícil obtener información fiable de pacientes que han sido reanimados tras fibrilación ventricular o copalso súbito, por lo que a la isquemia se le concede únicamente un papel predictivo o pronóstico [55]. Ha de considerarse además, la posible existencia de otros factores dinámicos (pasajeros) como causa de infarto de miocardio, tales como el vasoespasmo coronario y la agregación plaquetaria reversible. Esto es generalmente aceptado sobre la base de estudios angiográicos coronarios en pacientes con infarto agudo de miocardio.

Conviene señalar, que los efectos de la reperfusión suponen una dramática reducción sobre la tasa de taquicardia ventricular, con incremento de su estabilidad eléctrica [56], sin embargo la reperfusión tisular en sí conlleva un cierto riesgo de arritmias [57]. Pero el verdadero mecanismo de muerte súbita en individuos sin infarto antiguo, sin trombosis coronaria y con reducciones luminales coronarias inferiores al 50\%, todavía hoy permanece desconocido. Tal vez se deban a alteraciones en los canales del sodio que producen arritmias y muerte súbita, tal y como sucede en el síndrome del Q-T largo o en el síndrome de Brugada [44].

\section{CONSIDERACIONES FINALES}

Como acabamos de ver en las páginas precedentes, existe un alto porcentaje de errores inducidos por la exclusiva visión macroscópica de la autopsia médicolegal, todo lo cual indica la necesidad del estudio complementario anatomopatológico para dar una validez científica a sus conclusiones.

Semejante pretensión está lejos de alcanzarse, y solo se podrá conseguir mediante una mayor disponibilidad de las técnicas histopatológicas convencionales e inmunohistoquímicas en el momento de la autopsia, y a través de la imposición de una metodología sistemática de estudio de las muestras en aquellos casos de interés judicial.

No cabe duda de que la muerte súbita representa un auténtico problema sin resolver y una considerable alteración emocional en nuestra comunidad, especialmente cuando tiene lugar en individuos jóvenes y aparentemente sanos [58]. En una pequeña proporción de sujetos (generalmente jóvenes o de mediana edad) la causa de la muerte no puede ser descubierta ni aun después de una cuidadosa autopsia y de la práctica de numerosos exámenes complementarios, lo que nos induce a pensar en la existencia de una serie de procesos puramente funcionales, imposibles de evidenciar en estos momentos, mediante el estudio necrópsico.

Ante estos casos Davies [59] ha propuesto que admitamos nuestra ignorancia y registremos la causa de la muerte como "Síndrome de muerte súbita del adulto". Esto nos parece una postura honesta, al tiempo que nos proporciona una idea de la verdadera magnitud del problema y de la necesidad de seguir profundizando en el conocimiento del tema.

En conclusión, en los casos en los cuales se sospeche el desarrollo de un infarto de miocardio de corta evolución, es recomendable la utilización combinada de técnicas convencionales e inmunohistoquímicas, sin embargo estas últimas no sustituyen la interpretación macroscópica ni la autopsia en sí misma y los resultados deben correlacionarse con los hallazgos microscópicos convencionales, con los datos clínicos y con el resto de los exámenes complementarios realizados. 
Entre los anticuerpos ensayados, los marcadores de actina y desmina se han mostrado como los más efectivos para este tipo de diagnóstico. En estas circunstancias, la inmunohistoquímica, incrementando la seguridad del diagnóstico necrópsico.

Por otra parte y como hemos podido observar en el presente estudio, existe un porcentaje relativamente importante de casos (22\%) sin alteraciones histopatológicas sugestivas de isquemia miocárdica, por lo que la causa de la muerte podría atribuirse a un proceso estrictamente funcional. Sobre la base de estos hallazgos y de otros estudios similares, resulta razonable admitir el "Síndrome de muerte súbita del adulto" como una categoría diagnóstica independiente.

\section{BIBLIOGRAFÍA:}

I.- VARGAS SO, SAMPSON BA y SCHOEN FJ. (1999) Pathologic detection of early myocardial infarction: a critic review of the evolution and usefulness of modern technique. Mod Pathol, 12: 635-645.

2.- NISHIDA S, HIMURA S Y HASHIMOTO S. (1987) Immunohistochemical change of actin in experimental myocardial ischemia. Its usefulness to detect very early myocardial damages. Histol Histopath, 2: 4I7-428.

3.- EMANCIPATOR K, URANKAR-NAGY N, LEONARD KA, BRADFORD $G$ y EMANCIPATOR SN. (1992) Immunohistologic demonstration of myocardial proteins with applications. Am J Cardiov Pathol, 97:376-380

4.- ZHANG JM y RIDDICK L. (1996) Cytoskeleton immunohistochemical study of early ischemic myocardium. Forensic Sci Int, 80: 229-238.

5.- LEADBEATTER S, WAWMAN HM y JASANI B (1989). Immunocytochemical diagnosis of early myocardial ischaemic/hypoxia damage. Forensic Sci Int, 40:171-180.

6.- LEADBEATTER S, WAWMAN HM y JASANI B. (1990) Further evaluation of immunocytochemical staining in the diagnosis of early myocardial ischaemic/hypoxic damage. Forensic Sci Int, 45:I35-141.

7.- LÈGER J, CHEVALIER J, LARVE C y cols. (199I) Imaging of myocardial infarction in dogs and human using monoclonal antibodies specific for human myosin heavy chains. JACC, 18: 473-484.

8.- FUJIMOTO K, YASUE H, NAKAO K y cols. (1993) Novel monoclonal antibodies specific for human cardiac myosin light-chain I: useful tools for analysis of normal and pathological hearts. J Histochem-Cytochem, 41:35-42.

9.- FUJIWARA H, TANAKA M, MIYAZAKI S, MATSUDA M, KAWAI Ch y FUJIWARA T. (1988) Detection of early myocardial infarction in formalin-fixed, paraffin-embebed tissue. Am J Cardiovasc Pathol, 2: 57-61. 10.- BRINKMANN B, SEPULCHRE MA y FERCHNER G. (1993) The application of selected histochemical and immunohistochemical markers and procedure to the diagnosis of early myocardial damage. Int J Leg Med, 106:135-14I.

II. -ORTMANN C, PFEIFFER H y BRINKMANN B. (2000) A comparative study on the immunohistochemical detection of early myocardial damage. Int J Legal Med II3: 215-220.

12.- CHUMACHENKO PV y VIVERT AM. (199I) Immunomorphologic diagnosis of early myocardial necrosis using monoclonal antibodies to desmin and vimentin. Arch Pathol, 53:16-19.
I3.- THORNELL LE, HOLMBOM B, ERIKSSON A, REIZ S, MARKLUND S y NÄSLUND U. (1992) Enzyme and immunohistochemical assessment of myocardial damage after ischemia and reperfusion in a closed-chest pig model. Histochemistry, 98: 34I-353.

14.- AMBERG R, GUDAT F y MIHATSCH MJ. (1994) Immunomorphology of myocardial infarction. En Sudden Cardiac Death de Somogori E \& Sotonyi P. De. Semmelweis Kiadó. Budapest.

15.- HEIN S, SCHEFFOLD T y SCHAPER J. (1995) Ischemia induces early changes to cytoskeletal and contractile proteins in diseased human myocardium. J Thorac Cardiovasc Surg, I10: 89-98.

16.- THORNELL LE, ERIKSSON A, HOLMBOM B, JOHANSSON B y NÄSLUND U. (199I) Fibronectin and laminin related myocardial damage and repair. J Mol Cell Cardiol, 23 (Supl V): S I3.

17.- HANSEN SH y ROSSEN K. (1999) Evaluation of cardiac troponin I immunoreaction in autopsy hearts: a possible marker of early myocardial infarction. Forensic Sci Int, 99: 189-196.

18.- ENTMAN ML, MICHAEL LL, ROSSEN RD y cols. (199I) Inflammation in the course of early myocardial ischemia. FASEB J, 5: 2529-2537.

19.- SHEKHONIN BV, GURIEV SB, IRGASHEV SHB y KOTELIANSKII VE. (1990) Immunofluorescent identification of fibronectin and fibrinogen in experimental myocardial infarction. J Mol Cell Cardiol, 22: 533-54I.

20.- RAZA-AHMAD A. (1994) Fibrinogen: a diagnostic marker for early ischemia. Biotech-Histochem, 69: 268-272.

21.- Schäfer H, Mathey D, Hugo F y Bhakdi S. (1986) Deposition of the terminal C5b-9 Complement complex in infarted areas of human myocardium. J Immunol, I37:1945-1949.

22.- ROSSEN RD, MICHAEL LH, KAGIYAMA A y cols. (1988) Mechanism of Complement activation after coronary artery occlusion: Evidence that myocardial ischemia in dogs causes release of constituents of myocardial subcellular origin that complex with human Clq in vivo. Circ Reseach, 62: 572-584.

23.- THOMSEN H y SCHULTZ A. (1990) Immunohistochemical detection of C5b-9 complement complex in early stages of miocardial necrosis in paraffin sections. Rechtsmedizin, 103: 199-206.

24.- HUGO F, HAMDOCH T, MATHEY D, SCHÄFER H y BHAKDI S. (1990) Quantitative measurement of SC5b-9 and $C 5 b-9(\mathrm{~m})$ in infarcted areas of human myocardium. Clin Exp Immunol, 81: 132-136. 
25.- VÄKEVÄ A, LAURILA P y MERI S. (1992) Loss of expression of protectib (CD59) is associated with complement membrane attack complex deposition in myocardial infarction. Lab Invest, 67: 608-616.

26.- VÄKEVÄ A, LAURILA P y MERI S. (1993) Regulation of Complement Membrane Attack Complex Formation in Myocardial Infarction. Am J Pathol, 143: 65-75.

27.- EDSTON E y KAWA K. (1995) Immunohistochemical detection of early myocardial infarction. An evaluation of antibodies against the terminal complement complex (C5b-9). Int J Legal Med, I08: 27-30.

28.- THOMSEN H y HELD H. (1995) Immunohistochemical detection of $(5 \mathrm{~b}-9$ ( $\mathrm{m})$ in myocardium: an aid in distinguishing infarctioninduced ischemic heart muscle necrosis from other forms of lethal myocardial injury. Forensic Sci Int, 71: 87-95.

29.- DORAN JP, HOWIE AJ, TOWNEND JN y BONSER RS. (1996) Detection of myocardial infarction by immunohistochemical staining for $\mathrm{C} 9$ on formalin fixed, paraffin was embebed sections. J Clin Pathol, 49: 34-37.

30.- NIESSEN HW, LAGRAND WK, VISSER CA, MEIJER CJ y HACK CE. (I999) Upregulation of ICAM-I on cardiomyocytes in jeopardized human myocardium during infarction. Cardiovasc Res, 4I: 603-610.

3I.- FISHBEIN MC, KULBER D, STANCL M y EDWALDS G. (1986) Distribution of fibrinogen and albumin in normal, ischaemic, and necrotic myocardium during the evolution of myocardial infarction: an immunohistochemical study. Cardiovasc Res, 20: 36-4I.

32.- SIEGEL RJ, SAID JW, SHELL WE, CORSON G y FISHBEIN MC. (1984) Identification and localization of creatine kinase $B$ and $M$ in normal, ischemic and necrotic myocardium. An immunohistochemical study. J Mol Cell Cardiol, I6: 95-103.

33.- KLEINE AH, GLATZ JFC, HAVENITH MG, VAN NIEUWENHOVEN FA, VAN DER VUSSE GJ y BOSMAN FT. (1993) Immunohistochemical detection of very recent myocardial infarctions in humans with antibodies against heart-type fatty acid-binding protein. Cardiovasc Pathol, 2: 63-69.

34.- GIRALDO AA y HIGGINS MJ. (1988) Laboratory methods in the study of coronary atherosclerosis. Pathol Annual, 23:217-236.

35.- ELFAWAL MA y WHEATLEY DJ. (1989) Diagnosis of sudden coronary death in the autopsy room: guidelines for forensic pathologists. Med Sci Law, 29:64-68.

37.- DINGES HP, WIRNSBERGER G y HOFLER H. (1989) Immunocytochemistry in cytology. Comparative evaluation of different techniques. Anal Quant Cytol Histol; II:22-32.

38.- GUSTAFFSON B y MANSON J-C. (1987) Methodological aspects and application of the immunoperoxidase staining technique in diagnostic fine needle aspiration cytology. Diagn Cytopathol, 3: 68-73.

39.- SCOTTI TM y HACKEL D. (1985) Heart. En: Kissane JM, Anderson WAD (eds). Anderson's Patholoy. Mosby, St. Louis, p. 589.
36.- VOIGT JJ y DELSOL G. (1992) Immunohistochemistry on paraffin-embebed tissue sections-aplications. Apports et limites. Ann Pathol, I2: 58-60.

40.- SEIFERT PS, HUGO F, TRANUM-JENSEN J et al. Isolation and characterization of a complement-activating lipid extracted from human atherosclerotic lesions. J Exp Med, 1990; 172: 547-57.

4I.- LIBERTHSON RR, NAGEL EL, HIRSCHMAN JC y cols. (1974) Pathophysiologic observations in prehospital ventricular fibrillation and sudden cardiac death. Circulation, 49: 790-798.

42.- DAVIES MJ y THOMAS A. (1984) Thrombosis and acute coronary artery lesions in sudden cardiac death. $\mathrm{N}$ Eng J Med, 310: II37-II42.

43.- GREENE HL, RICHARDSON DW, BARKER AH y cols. (1989) Classification of death after myocardial infarction as arrhytmia or non arrhythmia (The Cardiac Arrhythmia Pilot Study). Am J Cardiol, 63: I-6.

44.- DAVIES MJ. (1999) The investigation of sudden cardiac death. Histopathology, 34: 93-98.

45.- CARBONI GP, LAHIRI A, CASHMAN PMM y RAFTERY EB. (1987)

Mechanism of arrhytmias accompanying ST-segment depression on ambulatory monitoring in stable angina pectoris. Am J Cardiol, 60. 1246-1253.

46.- WITT AL y JANSEN J]. (1992) Experimental models of ventricular tachycardia and ventricular fibrillation caused by ischaemia and infarction. Circulation, 85: 32-34.

47.- BIGGER T, WELD FM y ROLNITZKY LM. (198I) Prevalence, characteristics and significance of ventricular tachycardia (three or more complexes) detected with ambulatory electrocardiographic recording in the late hospital phase of acute myocardial infarction. Am J Cardiol, 48: 815-823.

48.- BIGGER JT, FLEISS JL, KLEIGER R, MILLER JP y ROLNITZKY LM. (1984) The Multicenter Post-infarction Research Group. The relationship among ventricular arrythmias, left ventricular dysfunction and mortality in the 2 years after myocardial infarction. Circulation, 69: 250-258.

49.- DE SOYZA N, BISSETT J, KANE J, MURPHY M y DOHERTY J. (1974) Ectopic ventricular prematurity and its relationship to ventricular tachycardia in acute myocardial infarction in men. Circulation, 50: 529-533.

50.- CAMPBELL R, MURRAY A y JULIAN D. (198I) Ventricular arrhytmias in the first 12 hours of acute myocardial infarction. $\mathrm{Br}$ Heart J, 46: 35I-357.

5I.- CHEEMA AN, SHEU K, PARKER M, KADISH A y GOLDBERGER J]. (1998) Nonsustained ventricular tachycardia in the setting of acute myocardial infarction: tachycardia characteristics and their prognostic implications. Circulation, 98: 2030-2036.

52.- BEHRENS S, LI C y FRANZ M. (1997) Effects of myocardial ischaemia on ventricular fibrillation inductibility and defribillation efficacy. J Am Coll Cardiol, 29: 817-824. 
53.- PEPINE CJ, GOTTLIEB SO y MORGANROTH J. (199I) Ambulatory ischaemia and sudden death: an analysis of 35 cases of death during ambulatory ECG monitoring. J Am Coll Cardiol, 17: $63 \mathrm{~A}$.

54.- GOLDSTEIN S, MEDENDORP SV, LANDRIS JR y cols (1996). Analysis of cardiac symptoms preceding cardiac arrest. Am J Cardiol, 58: I195-1198.

55.- PODRID P. (1990) Silent ischaemia, ventricular arrhythmia and sudden cardiac death. J Am Coll Cardiol, 16: 55-56.

56.- OPITZ CF, FINN PV, PFEFER MA, MITCHELL GF y PFEFFER JM. (1998) Effects of reperfusion on arrhytmias and death after coro- nary artery occlusion in the rat: increased electrical stability independent of myocardial salvage. J Am Col Cardiol, 32: 26I-267.

57.- ALEXOPOULOS D, COLLINS R, ADAMOPOULOS S, PETO R y SLEIGHT P. (199I) Holter monitoring of ventricular arrhytmias in a randomised, controlled study of intravenous sptreptokinase in acute myocardial infarction. Br Heart J, 65: 9-13.

58.- LAMBERT EC, MENON VA, WAGNER HR y VLAD P. (1974) Sudden unexpected death from cardiovascular disease in children: a cooperative international study. Am J Cardiol, 34:89-96.

59.- DAVIES MJ. (1992) Unexplained death in fit young people. $\mathrm{Br}$ Med J; 305:538.-539. 